\title{
Comment
}

Iris holes are occasionally encountered which are unaccompanied by evidence of a penetrating injury, old or recent. Most of these holes are congenital in origin, and the possibility that the hole described here was of this nature cannot be excluded. However, the most likely explanation in this case would appear to be that, at one particular locus, the concussion forces which produced the iris atrophy were severe enough to split the pigment epithelium as well as the stroma.

The author wishes to thank Mr. P. McG. Moffatt, under whose care this boy was admitted, for permission to publish this case.

\section{PARALYSIS OF ACCOMMODATION WITH RECOVERY AFTER 5 YEARS*}

\author{
BY \\ R. W. STEPHENSON \\ Cheltenham
}

\begin{abstract}
A boy aged 10 years was first seen on August 19, 1952, when he had suddenly noticed that he could not read at school. His distance vision was clear. There was found to be a bilateral isolated complete paralysis of accommodation. There had been no relative illness and a detailed investigation revealed no other organic abnormality.

He was seen by Mr. Keith Lyle, Mr. G. Cashell, and Dr. Meadows, and the diagnosis was confirmed by all. It was suggested that the probable aetiology was a sub-clinical diphtheria and recovery was expected within a year.

Bifocal lenses were prescribed and the patient was seen at regular intervals, but no recovery took place, and in January, 1958, $5 \frac{1}{2}$ years after the onset of the condition, there was still a complete bilateral paralysis of accommodation.

Only 4 months later, however, in May, 1958, the boy's father reported that the boy was reading without glasses, and examination showed a complete recovery with full normal power of accommodation.

When last seen on July 21,1959 , he was slightly myopic and required a correction of $-0.75 \mathrm{D}$ sph. in the right eye and $-1 \mathrm{D}$ sph. in the left. This had developed only during the past year, for he had previously needed a slight hypermetropic correction for distance. The accommodation is to $8 \mathrm{~cm}$., uniocular and binocular.
\end{abstract}

\section{Comment}

It is usually considered that in such cases recovery from a paralysis of accommodation will take place within a year. In this case there was no sign of any recovery for $5 \frac{1}{2}$ years, but 6 months later recovery was complete.

* Received for publication July 29, 1959. 